\title{
Abdominal Radiology: a new name for an evolutionary change
}

\author{
C. Daniel Johnson, M.D. \\ Department of Radiology, Mayo Clinic Arizona, Scottsdale, AZ, USA
}

This first issue of Abdominal Radiology marks the continued evolution of the Journal to meet the professional needs of the Abdominal Radiologist. With this change in title from Abdominal Imaging, the inclusion and welcoming of interventional radiology manuscripts into the Journal is formalized. Many abdominal radiologists have had an active interventional practice for years, but without a central academic home for their education and publications. As the official journal of the Society of Abdominal Radiologists (SAR) that is inclusive of interventional radiologists, it is only fitting to expand the vision of the journal to include these important components of our practice. Readers should look for a growing presence of interventional articles in the future, and authors should consider sending us their interventional manuscripts for consideration.

Beginning in 2016, Abdominal Radiology will become a monthly publication, secondary to your strong support of submitting many high quality manuscripts for consideration. Please continue to send us your best work. Original articles that advance the science and have wide readership appeal will continue to be encouraged and are the centerpiece of Journal activity. Special focus sections, review articles, classics in Radiology, and practice related articles will also continue. Continuing medical education (CME) credits with self assessment (SA) will be offered with each issue - allowing our readers to record credit for their educational effort and learning in support of maintenance of certification.

We will strive to continue to earn the respect of our international readers as we have now affiliated with the Asian Society of Abdominal Radiology (ASAR) and the European Society of Gastrointestinal Radiology. We strive to increase international contributions and collaboration.

A special thanks to the enormous volunteer efforts that makes this Journal possible. An army of associate editors, reviewers and editorial board members around the world are all working hard to find the best articles, and to ensure the scientific integrity of these publications. These individuals truly value learning, science, and selfless dedication to the cause of advancing patient care. I am indebted to all of them. I hope you will find professional satisfaction and assistance as you become regular monthly readers of this new Journal. I would welcome your input and suggestions as we continue to strive for ongoing improvements.

Editor-in-Chief 